\title{
AIBR IBEROAMERICANA
}

\section{ESTIMADO LECTOR/A:}

Gracias por descargar este artículo. El texto que está a punto de consultar es de acceso libre y gratuito gracias al trabajo y la colaboración desinteresada de un amplio colectivo de profesionales de nuestra disciplina.

Usted puede ayudarnos a incrementar la calidad y a mantener la libre difusión de los contenidos de esta revista a través de su afiliación a la asociación AIBR:

\section{http://www.aibr.org/antropologia/aibr/socios.php}

\section{LA ASOCIACIÓN A AIBR LE PROPORCIONARÁ UNA SERIE DE VENTAJAS Y PRIVILEGIOS, ENTRE OTROS:}

1. Recibir en su domicilio la revista impresa, en Europa y América (tres números anuales).

2. Derecho a voto en las asambleas de socios, así como a presentarse como candidato a la elección de su Junta Directiva.

3. Acceso al boletín de socios (tres números anuales), así como la información económica relativa a cuentas anuales de la asociación.

4. Beneficiarse de las reducciones de precio en congresos, cursos, libros y todos aquellos convenios a los que a nivel corporativo AIBR llegue con otras entidades (incluidos los congresos trianuales de la FAAEE).

5. Promoción gratuita, tanto a través de la revista electrónica como de la revista impresa, de aquellas publicaciones de las que sea autor y que estén registradas con ISBN. La difusión se realiza entre más de 6.700 antropólogos suscritos a la revista.

6. Cuenta de correo electrónico de la forma socio@aibr.org, para consultar a través de webmail o cualquier programa externo.

7. Promoción de los eventos que organice usted o su institución.

8. Opción a formar parte como miembro evaluador del consejo de la revista.

IMPORTE DE LA CUOTA ANUAL: ACTUALMENTE, LA CUOTA ANUAL ES DE 34 EUROS PARA MIEMBROS INDIVIDUALES.

Su validez es de un año a partir del pago de la cuota. Por favor, revise la actualización de cuotas en nuestra web.

MEMBRESÍA INSTITUCIONAL Y DEPARTAMENTAL: Si usted representa a una institución o departamento universitario, compruebe cómo aprovechar al máximo la red de AIBR para su entidad: http://entidades.aibr.org 


\section{RESUMEN:}

El artículo traza un itinerario circular que parte de la experiencia musical en su sentido tradicional de interacción y actividad grupal, sigue con algunas de las características de la figura moderna del oyente solitario y su relación con el espacio público y privado, y termina con las nuevas tecnologías de la información y las redes sociales de la web 2.0, las cuales hacen posible nuevas formas de interactividad y nuevas maneras de fortalecer los lazos de afiliación y sociabilidad a través de la música, hecho que aquí interpretamos como un retorno a los orígenes grupales y comunitarios de la experiencia musical.

\section{PALABRAS CLAVE:}

Interacción, oyente solitario, espacio público, espacio privado, redes sociales.

\section{SUMMARY:}

The paper outlines a circular tour that starts with the musical experience in his traditional sense of interaction and group activity, continues with some of the characteristics of the modern figure of the solitary listener and his relation to public and private space, and ends with the new information technologies and social networks of the Web 2.0, which make possible new forms of interactivity and new ways of strengthening the bonds of affiliation and sociability through music, fact that here we interpreted as a return to the group and community roots of the musical experience.

\section{KEY WORDS:}

Interaction, solitary listener, public space, private space, social networks. 


\section{Introducción: En el principio fue la interacción}

A pesar de que no conocemos a ciencia cierta el origen de la música, para muchos un verdadero misterio, parece que desde sus inicios más tempranos ha jugado un papel fundamental en la interacción social. Los etnomusicólogos, muy especialmente, suelen poner énfasis en la importancia colectiva de la música en las culturas que estudian. Tal es el caso de John Blacking, para quien la música tiene que ver con sentimientos humanos y experiencias en sociedad, de tal forma que: "Muchos de los procesos musicales esenciales, si no todos, se hallan en la constitución del cuerpo humano y en patrones de interacción entre cuerpos humanos en sociedad" (Blacking, 2006: 25). En las sociedades denominadas por comodidad primitivas o tradicionales, la música suele acompañar ceremonias religiosas y otras actividades grupales, tiene la cualidad de reunir a la gente en hermandad y compartir una experiencia social. En general, estas sociedades poseen una concepcion del individuo integrado en la colectividad. Las actividades rituales y estéticas son parte de la existencia social y, por tanto, no diferencian la música como una actividad distinta de las demás, como algo especial o exclusivo sólo al alcance de unos pocos. Como recuerda Anthony Storr, hoy en día "estamos tan acostumbrados a pensar en la respuesta individual a la música que solemos olvidar que, durante gran parte de nuestra historia, la música ha sido, ante todo, una actividad grupal" y que, desde un principio, "tuvo una finalidad comunitaria" (Storr, 2007: 51).

En las sociedades modernas, la música se ha seguido utilizando como acompañamiento de actividades colectivas, como complemento de actos sociales y celebraciones públicas. En tales situaciones, compartimos con las sociedades primitivas algunas de las funciones originales de la música, "consistentes en ensalzar la importancia de los eventos públicos y alentar la solidaridad social" (Storr, 2007: 179). Sin embargo, existe una diferencia fundamental entre ambas, que reside en el hecho de que muchas de las acciones que acompañan las actividades grupales en las sociedades primitivas están disociadas y desacralizadas en nuestras sociedades. Los registros aparecen disociados, mientras que, en las sociedades primitivas, se da una conjunción de lo religioso, lo político, lo social, lo musical, etc. En estas sociedades, por lo general, la diferencia entre trabajo y no-trabajo no es tan nítida como en la sociedad occidental, entremezclándose en muchas ocaciones: "lo que actualmente pertenece a la categoría del deporte, el ocio, el juego, estaba integrado en las actividades sociales del grupo y revestía funciones plurales" (Segalen, 2005: 75). En nuestras sociedades, 
la música se asocia con el no-trabajo y sirve de acompañamiento para actos y celebraciones colectivas que llenan el espacio contemporáneo de signos rituales. Estos actos suponen una ruptura esporádica con la rutina diaria y conforman espacios de una comunión colectiva de la que se carece en la vida cotidiana. Todo lo contrario que en muchas sociedades primitivas, donde la música es una parte más de la existencia social y no se concibe como un acto diferenciado: no es un complemento ocasional, sino una parte integral de la vida y la sociedad.

El que la música fuera una parte tan importante e inseparable de la vida de las sociedades premodernas tiene mucho que ver con el "anclaje" (Giddens, 1993) de las actividades sociales y artísticas a contextos locales o territoriales de interacción, los cuales conforman comunidades basadas en la interacción efectiva entre personas con fuertes vínculos afectivos y culturales (Abril, 2005: 50). De ahí que el origen de la música, como señalábamos al principio, esté ligado a la interacción social. Con la llegada del mundo moderno, numerosas actividades (la propia música entre ellas) y formas de relación social se fueron desarraigando, "desanclando", de estos contextos locales o territoriales de interacción cara a cara, para reconstituirse en espacios distanciados, no presenciales. Surge entonces el cambio de la Gemeinschaft a la Gesseilschaft (Tönnies) o, si se prefiere, de las "solidaridades mecánicas" a las "solidaridades orgánicas" (Durkheim), que privan al individuo de un apoyo colectivo y afectivo (de padres, amigos o vecinos) y le dejan en su soledad íntima frente al resto de personas, que son ahora completos desconocidos.

En este sentido, acierta Storr al señalar que el oyente de música en solitario es un personaje moderno, nacido a raíz de este paso de las sociedades tradicionales basadas en el "anclaje" espaciotemporal, en la experiencia inmediata, cara a cara, a las sociedades modernas del "desanclaje”. Y acierta también al recordarnos que este oyente solitario se vale de la tecnología moderna y, por lo tanto, "es un recién llegado en términos históricos" (Storr: 2007: 179).

\section{El camino hacia el oyente solitario}

Cuando la tecnología occidental hace posible, a finales del siglo XIX, la grabación y fijación de los sonidos, la música se vuelve una industria y su consumo deja de ser principalmente colectivo: deja de ser relación directa, puesta en escena, ritual o espectáculo, para convertirse en escucha solitaria, en un signo almacenable que va a transformar profundamente la relación de cada uno con la música, sobre todo a partir de la genera- 
lización del single como formato de consumo. ${ }^{1} \mathrm{Al}$ principio, esta transformación se vincula principalmente a la soledad del oyente, de la misma forma que la invención de la imprenta se asoció con la lectura solitaria y silenciosa frente a la lectura en grupo. La analogía con la imprenta no es caprichosa. Umberto Eco, sin ir más lejos, nos recuerda que la llegada de la música reproducida "ha cambiado las condiciones de consumo y de la producción musical en la misma medida en que la imprenta cambió las condiciones de la lectura y de la producción literaria” (Eco, 2000: 289).

En su célebre ensayo sobre la figura del narrador, Walter Benjamin (1986) opuso la novela, producto paradigmático de la modernidad, a la narración (en su sentido de oralidad). Lo que distingue a la novela de la narración es su dependencia de libro y el hecho de que lleve implícita la idea de soledad: "la cámara de nacimiento de la novela es el individuo en su soledad", dice Benjamin. La novela conduce a la separación entre el autor y el lector, observable a varios niveles: por una parte, la división del trabajo conduce a una profesionalización de los narradores y a su "desanclaje" de la comunidad narrativa tradicional; por otra parte, la mediación de la escritura hace que una relación que era característicamente social, cara a cara, se transforme en una relación entre un sujeto lector aislado y un objeto textual que permite una objetivación del texto que resultaba imposible en una cultura oral (Abril, 2005: 58). Lo mismo ocurre en el caso de la música reproducida: se produce una creciente profesionalización del músico por la que se requieren valiosos intérpretes para ejecuciones de alto nivel que son grabadas y puestas en venta para su reproducción. Asimismo, la mediación de la grabación hace que la experiencia directa, inmediata y presencial de la música "oral” pase a transformarse en una relación entre un oyente aislado y un objeto textual (la música grabada o "enlatada") que inaugura una nueva forma de experiencia y consumo musical sin precedentes.

Ya hemos visto cómo en las sociedades tradicionales la música era una experiencia presencial, inseparable de la vida y la sociedad y "anclada" a un contexto local o territorial determinado. Pero incluso cuando la música se desarraiga de esos contextos, en figuras como la del juglar, sigue basándose en la relación directa, cara a cara. Como señala Jacques Attali (1995), durante toda la Edad Media, el juglar permanece fuera de

1. Poseer música grabada a principios del siglo XX era un signo de acomodo social. Así como en el pasado la radio o el gramófono no estuvieron al alcance de todos, sino de familias pudientes, entre la patente del disco y su uso como producto de ocio pasó un periodo de tiempo considerable, y no será hasta la difusión del single cuando el consumo de música grabada alcance su máxima democratización, al abaratarse los costes de producción y de venta al público. 
la sociedad. Se desplaza por los territorios para proponer sus servicios a domicilio: él "es" la música y el espectáculo del cuerpo; él la crea, la porta, la organiza y la ofrece en directo a todo tipo de consumidores de música, independientemente de la clase social. Así, campesinos, artesanos, burgueses y nobles disfrutan de un mensaje musical que circula por las sociedades y cuyo repertorio es muchas veces el mismo. A pesar de ser una música desarraigada de un contexto específico, sigue siendo una música social y presencial, que se consume y experimenta cara a cara en los distintos lugares por los que transita el juglar. Sin embargo, a diferencia de las sociedades primitivas, se desacraliza y disocia de todo lo demás y, por tanto, es concebida como una entidad diferenciada, reservada para fiestas cíclicas, bodas, banquetes anuales, etc.

La música vuelve a "anclarse" cuando las cortes excluyen a los juglares, voz del pueblo, y convierten al músico en menestral o menestrier (de ministeralis, funcionario). En tres siglos, del XIV al XVI, recuerda Attali, el músico deja de ser nómada para quedar fijado a una corte y a una determinada ciudad. Las cortes convierten al músico en sirviente y sólo escucharán música escrita sobre partitura y ejecutada por músicos asalariados, quienes hacen de la música un ocio o pasatiempo para sus señores. El carácter ocioso de la música se generaliza cuando la sala de conciertos abre sus puertas al gran público. Aquí, el músico ya no actúa para una corte sino para un amplio público que paga una entrada que le da derecho a disfrutar del espectáculo. La música sigue siendo algo presencial, inmediato. Sin embargo, se va estableciendo una mayor distinción entre la figura del intérprete y la del oyente, distinción que culminará con la tecnología de la grabación. Lo más significativo de todo esto es que la música como entidad diferenciada y elemento único por derecho propio resulta cada vez más importante, lo que aleja su sentido y propósito del que tenía en las sociedades primitivas: la función ya no es tan sólo ritual, sino que tiene el añadido del consumismo.

Todas estas formas de experiencia musical se basan en lo que Attali denomina red de la representación y que se caracteriza por un espectáculo al que se asiste en lugares específicos: campos cerrados, domicilios particulares, cortes, salas de concierto, etc. El valor de la música aquí es su valor de uso como espectáculo y puesta en escena: valor de la experiencia espaciotemporal presencial e inmediata. Dicho más sencillamente, es representación lo que surge de un acto único que se vive y experimenta aquí y ahora, in situ. La naturaleza de la representación se ve alterada por el surgimiento de una nueva red: la de la repetición. Esta red aparece en el siglo XIX con las grabaciones, y es concebida como modo de 
conservación de la representación, lo cual genera una nueva forma de organización de la economía:

Cada espectador tiene una relación solitaria con un objeto material; el consumo de música se vuelve individual, simulacro del ritual sacrificial y espectáculo ciego. La red ya no es aquí una forma de sociabilidad, ocasión de encuentro y comunicación de los espectadores, sino instrumento de accesibilidad formidable a un depósito individualizado de la música. Ahí también, la nueva red aparece en la misma música como anuncio de una nueva etapa de organización del capitalismo, el de la producción en serie, repetitiva, de todas las relaciones sociales (Attali, 1995: 52).

La distinción entre representación y repetición resulta fundamental ya que cada uno de estos modos de organización remite a una lógica muy diferente: la representación proporciona un valor de uso ligado a la cualidad humana de la producción, mientras que la repetición permite el almacenamiento, la accesibilidad y la repetición; en la representación, se entiende que se trata de una obra de una sola vez, momento único y excepcional, mientras que en la repetición es posible un stock de audiciones posibles; la relación que se desprende de la representación es de tipo presencial, donde autor/intérprete y lector/oyente se encuentran en el mismo contexto espaciotemporal, mientras que la relación de la repetición está mediada tecnológicamente y pertenece al orden de la reproducción y de la no-presencia y experiencia cara a cara. Así pues, el paso de la representación a la repetición significa el nacimiento de la figura moderna del oyente solitario, aquel que prefiere disfrutar de la música en la intimidad de su hogar a formar parte del colectivo espontáneo del espectáculo.

\section{La perfección técnica de la grabación}

El nacimiento de la música reproducida transforma completamente el carácter del consumo y la escucha de música y, en consecuencia, la propia naturaleza de ésta. El hecho de poder almacenar el espectáculo o la performance musical y repetirla hasta el infinito, hace que "muchos oyentes prefieran la versión grabada, a la cual se han acostumbrado, a las ejecuciones en vivo, que pueden parecerles deficientes en comparación" (Yúdice, 2007: 38). Si bien en un principio la tecnología de grabación ofrece una calidad musical inferior a la que puede escucharse en directo, poco a poco, el producto va mejorando técnicamente, y con la llegada 
de los equipos de alta fidelidad (high fidelity o hi-fi) se logra alcanzar unas condiciones de audición ideales. La importancia de la música para el oyente solitario aumenta a medida que la tecnología progresa, lo que confirma la tesis de Storr (2007) del oyente de música en solitario como figura que nace con los inventos modernos que le van permitiendo, cada vez más, disfrutar aisladamente de ella.

La música grabada convierte el hogar familiar en una "minisala de conciertos" para el disfrute individual. ${ }^{2}$ Así, "Si antes se necesitaba ser parte de un público frente a músicos que ejecutaban una pieza, con el fonógrafo se podía prescindir de aquéllos y no se tenía que ir a una sala de conciertos" (Yúdice, 2007: 37-38). ${ }^{3}$ Esta situación afecta a la misma naturaleza de la producción musical, ya que la música tiende a ser cada vez más un producto pensado directamente para la grabación, y no pensado, interpretado y después grabado. Los métodos modernos de grabación musical pueden eliminar la espontaneidad interpretativa mediante el "montaje" de fragmentos que se han repetido para eliminar los fallos y errores. ${ }^{4}$ Así, en relación con el nuevo proceso de producción de la música basada en la repetición, Attali se quejaba de que

lo imprevisto y el riesgo de la representación desaparecen en la repetición. La nueva estética de la interpretación excluye el error, el titubeo, el ruido. Fija la obra fuera de la fiesta y del espectáculo, y la reconstruye y la manipula, formalmente, con una perfección abstracta. Esta visión hace olvidar poco a poco que la música era ruido de fondo y forma de vida, duda y balbuceo. La representación comunica una energía; la repetición produce una información sin ruido (Attali, 1995: 157).

La red de la repetición, de la mercancía y la producción en serie, no tolera los fallos (el error, el titubeo, el ruido) y reduce la espontaneidad y el estilo interpretativo de cada músico a una perfección técnica en consonancia con los equipos que han de reproducir la grabación resultante. Jean Baudrillard describió esta situación del siguiente modo:

\footnotetext{
2. El uso de la música grabada extiende y generaliza esta idea del salón doméstico como "minisala de conciertos", pero sus orígenes pueden rastrearse en algunos hogares del siglo XVIII donde la pianola u otros instrumentos musicales servían para amenizar las veladas familiares.

3. Como en el caso del disco comentado anteriormente, conviene insistir en que no todo el mundo disponía de fonógrafo. Tan sólo a partir de la venta de equipos más livianos y baratos de $h i-f i$ se hizo masiva esta necesidad de desprenderse del directo.

4. Esto ocurrirá en el mundo sinfónico a partir de los montajes de Leopold Stokowski, seleccionando los mejores planos de sonido grabados desde diferentes perspectivas de la orquesta.
} 
¿Dónde comienza el efecto estéreo, el punto de sofisticación inútil de la hi-fi, en que la música se pierde por la obsesión de su fidelidad? [...] Hoy, la obsesión por este tecnicismo, por esta veracidad, nos aleja definitivamente de la música. Ha creado un falso destino para la música [...] el de realizarse sólo en la perfección de su ejecución (Baudrillard, 1989: 75).

Asimismo, el sociólogo Richard Sennett, valiéndose de su conocimiento profesional de la música como ex concertista de violonchelo, señala que la esencia misma de la actuación en directo es que uno continúa al margen de las equivocaciones que cometa: "A menos que uno tenga una gran presencia, y una gran estima pública, detenerse en mitad de una pieza y volver a empezar es un pecado imperdonable" (Sennett, 2002: 634-635). Las grabaciones, sin embargo, no siguen la misma lógica, no se basan en una lectura continua a través de una pieza sino en una lectura fragmentada que permite que se graben pequeñas secciones, se vuelvan a grabar, sean corregidas por los técnicos o por el propio artista, "de modo que cada grabación constituye un collage de perfectos detalles”. El problema con la grabación, concluye Sennett, "consiste más bien en su misma perfección”.

La perfección técnica de la música grabada hace que el oído de la gente se acostumbre a escuchar música de un refinamiento absoluto (con la salvedad de géneros como la música punk o "de garaje”, que persiguen deliberadamente todo lo contario, o la música rock, que se rige por la ética del sonido vivo y por valores de honestidad y naturalidad). Los medios técnicos de grabación permiten producir actuaciones musicales de una perfección tal que raramente se pueden igualar en directo. Ahí tenemos ejemplos como la búsqueda de una interpretación ideal o sublime en el terreno de la música clásica (que se consigue ensamblando los segmentos más inspirados) o discos como el Pet Sounds de los Beach Boys o el Sgt. Pepper's..., de los Beatles, verdaderos precursores en técnicas de sonido y grabación. Esto hace que, como recuerda Storr, la audición repetitiva de una pieza en particular pueda provocar que el oyente acabe creyendo que esa interpretación a la que ha terminado acostumbrándose sea la única posible. Aquí se hace patente la diferencia entre una música reproducida, basada en el régimen de la repetición, y una música interpretada, basada en la representación, que incorpora una espontaneidad interpretativa y un compromiso emocional por parte de los músicos, "incompatible con una insistencia obsesiva en la perfección” (Storr, 2007: 181). 


\section{La música como rumor}

La tecnología moderna hace que el público tenga acceso a una variedad musical como en ningún otro momento de la historia, algo que terminará generalizándose con Internet y el advenimiento de la denominada "era del acceso" (Rifkin, 2000). En la red de la repetición, la accesibilidad sustituye a la fiesta, al espectáculo, al ritual. Así, una obra que su autor quizá no escuchó ni dos veces en su vida (caso de la $9^{a}$ Sinfonía de Beethoven y de la mayor parte de las obras de Mozart) se vuelve accesible a una multitud y es repetible fuera de su espectáculo. Gana una disponibilidad pero pierde su carácter festivo, y deja de ser ese acontecimiento único, excepcional, que era escuchado una vez por una minoría, para convertirse en repetición y mercancía, en signo almacenable (Attali, 1995: 149). Los inventos modernos, ya sea el disco, la radio o el juke box, permiten una extrema disponibilidad del producto sonoro e introducen en el aprecio musical a millones de oyentes que antes no podían acceder a un repertorio musical de tales dimensiones. Se produce entonces una cierta "democratización de la audición" y una "difusión del repertorio" que amplía la cultura musical de las clases medias y populares (Eco, 2001). Sin embargo, nos recuerda el propio Eco en una observación que llega hasta nuestros días, nace el punto de si esta extrema disponibilidad de la música, al eliminar el esfuerzo que había que hacer antes para "merecérsela" (como el peregrinaje hasta la sala de conciertos), "no contribuye a embotar la sensibilidad y a reducir la música a un objeto que ya no es de 'audición' consciente, sino de trasfondo sonoro 'percibido' como complemento habitual de otras operaciones domésticas”, como la lectura, la comida, la conversación, el amor, etc., operaciones que se desarrollan en este "acuario sonoro" en el que la música ya no se consume como música sino como "rumor", como una especie de "continuum musical en el que paulatinamente acabarán confundiéndose hasta los caracteres, el título, los autores y la calidad de las diversas ejecuciones" (Eco, 2001: 301). Aquí, Eco se está refiriendo sobre todo al flujo ininterrumpido de la radio, cuyo hilo musical y ritmo acelerado somete la sensibilidad a una especie de excitación neurótica que termina acostumbrando al público a aceptar la música como complemento o "columna" sonora de la propia jornada, evitando una escucha atenta y críticamente sensible incapaz de enfrentarse a tal cantidad de información y abundancia musical, tal y como ocurre hoy en día con Internet.

La accesibilidad y disponibilidad de la música conducen a su almacenamiento (stock) ya que no existe tiempo material para escuchar todo lo que queremos: "Se compran más discos de los que se pueden escuchar. 
Se almacena lo que se querría encontrar tiempo para escuchar. Tiempo de uso y tiempo de cambio se destruyen mutuamente", recuerda Attali (1995: 151). La lógica de la repetición, sujeta al ritmo acelerado de la producción en serie, crea una música que debe consumirse rápidamente y envejecer pronto, de modo que se cree la necesidad de un nuevo producto ya que todo puede ser sustituido por otra cosa. Tal es la forma de trabajo en la producción industrial masiva: la de la repetición de lo siempre igual, la misma que conduce al nacimiento de una nueva música, de una nueva canción, que no existen por sí mismas, sino como un "ornamento o encubrimiento tras el cual acecha lo siempre igual" (Adorno, 2009: 208). El acecho de lo siempre igual, de ese "eterno retorno de lo mismo" (Benjamin), la encuentra Adorno en las canciones de moda de la denominada por comodidad "música ligera", donde se produce la contradicción de, por una parte, desear incitar la atención del oyente, es decir, "diferenciarse de otras canciones de moda cuando tiene que venderse y llegar de lleno al oyente" y, por otra, no poder ir más allá de lo habitual, ya que debe seguir siendo poco llamativa y no rebasar "el lenguaje natural que parece natural al oyente medio y planeado por la producción” (Adorno, 2009: 210). Asimismo, la difusión de la música ligera, recuerda Eco, contribuye a una cierta "universalización del gusto" en la que todo pueblo consume y goza del mismo género de música, ya sea a través de discos, de la radio o de los juke boxes.

Se produce entonces una suerte de retorno parcial al estatus anterior a la red de la repetición, es decir, a la representación, donde la música ya no se escucha en silencio: se integra a una totalidad, pero como "ruido de fondo" o "rumor" sonoro. Asimismo, el oyente solitario no está tan sólo como parece pues se integra en una comunidad imaginaria o estética con la que comparte ciertas sensibilidades, vocabularios experienciales característicos, repertorios musicales, iconográficos, etc. Estas comunidades, señala Abril, "más que en interacciones cara a cara, se sustentan en la reelaboración de fragmentos discursivos de la cultura mediática, una cultura transnacional o cuando menos no local ni territorial" (Abril, 2005: 55-56). Así pues, el "desanclaje" territorial, físico, se compensa con un "anclaje" imaginario, virtual, que está en la base del capitalismo de consumo, ya que este último sería inconcebible sin la existencia de estas comunidades imaginarias "a través de las cuales el mercado regula y sanciona la expresión púbica de los deseos, las identidades, la asignación de prestigio, la competitividad consumidora -e indirectamente la productiva" (Abril, 2005: 56). ${ }^{5}$

5. Aunque esta es la tendencia general, existen otros compartimentos (música clásica, ópera, músicas folclóricas, etc.) que se mueven por otras lógicas, no puramente comerciales. 


\section{Música privada y espacio público}

Si bien en un principio la música reproducida se consume principalmente en el hogar doméstico, convertido, como ya dijimos, en una "minisala de conciertos" para disfrute personal que transforma la experiencia musical, los avances técnicos van reduciendo poco a poco el tamaño de los aparatos de reproducción y permitiendo a los oyentes transportar sus equipos de sonido del espacio privado de sus hogares al espacio público de la calle. Tal es el caso de la radio, que "a partir del uso de transistores y luego de pilas, a mediados del siglo XX, se volvió un instrumento pequeño y liviano para transportar sonidos, información y entretenimiento" (García Canclini, 2007: 64). Esta reducción de tamaño, unido a unos precios cada vez más asequibles, va permitiendo a los oyentes reunir sus propias experiencias musicales en los espacios que escojan:

Anteriormente, las radios habían sido unos muebles enormes y caros que había que colocar en la sala de estar y casi siempre bajo la vigilancia de los padres. Con la llegada del transistor portátil, se podía llevar fácilmente la radio al trabajo, a la playa, al colegio o al dormitorio de cada uno, algo que facilitó enormemente el que se apreciara la música pregrabada ya que permitía que cada uno se abstrajera del resto de personas que le rodeaba (Peterson y Ryan, 2005: 273)

El espacio musical ya no tiene por qué ser fijo. La música se vuelve cada vez más móvil y la figura del oyente solitario sale a la calle para abstraerse musicalmente entre la multitud, produciéndose la paradoja de una audición privada en el espacio público que alcanza su máxima expresión en nuestros días con el iPod y los reproductores portátiles de MP3.

Sin embargo, como recuerdan Yúdice y García Canclini, la salida de la música reproducida al espacio público tiene en un principio un alto componente de sociabilidad y de participación corporal. Esta salida comienza a finales de los años 70 con las boomboxes, unos sistemas portátiles de estéreo capaces de reproducir música de estaciones de radio o grabada (usualmente en cassettes) con una relativa potencia de sonido. Las boomboxes se asocian a la cultura hip hop (y a prácticas derivadas como el breakdance o el graffiti), que surge en las comunidades afroamericanas de barrios populares neoyorquinos como el Bronx, Queens o Brooklyn. Mucho se debatió entonces acerca de la "toma" del espacio público por jóvenes marginales (afroamericanos y latinos, en su mayoría) que se reunían y bailaban en las calles en torno a esas boomboxes 
que emitían una música a todo volumen. Como señala Yúdice, muchos percibieron esta salida al espacio público como ruido e incluso como agresión racial ya que esa ruidosa sonoridad fue asociada al crimen por contigüidad con los guetos de donde provenían estos jóvenes. La actitud despectiva hacia ellos quedo registrada en el nombre que se utilizó para caracterizar a sus boomboxes: guettoblasters o "detonadores del gueto" (Yúdice, 2007: 39). A pesar de los esfuerzos de la "buena sociedad" por acallar estas reuniones y eliminar el hip hop de las calles y parques de la clase media, hoy en día es uno de los géneros musicales más universales y sigue siendo una música eminentemente social y participativa con una idea muy fuerte de comunidad.

Pero la "toma" musical y estilística del espacio público no es ni mucho menos un fenómeno privativo del hip hop estadounidense. La encontramos también en las raves europeas de música electrónica, en las favelas brasileñas, en el rap de los banlieues parisinos, etc. La música en estos espacios actúa como factor de socialización y participación estética y corporal para los que se reúnen e interactúan en torno a ella, pero también interviene como elemento perturbador del orden social, al ser vista por muchos otros como ruido.

Todo esto cambia con la llegada del walkman, ya que los auriculares no se prestan a una experiencia colectiva. El uso del walkman implica lo contrario que las boomboxes ya que, lejos de enfrentar a los otros, los auriculares abrigan la experiencia de la audición privada del individuo, que circula en pleno espacio público pero cuya banda sonora interna no molesta a los demás. ${ }^{6}$ Puede que la molestia fuera en un principio visual, pues "llevar la vida privada al espacio público causaba extrañamiento, y todavía lo hace, si bien ya nos estamos acostumbrando a ver a los [...] que 'hablan consigo mismos' o a los enchufados a su walkman o iPod" (Yúdice, 2007: 37), pero ya no lo es tanto auditiva, musical, ruidosa.

El individuo se sumerge en sí mismo a través de una música, de una "banda sonora", que le acompaña en sus trayectos y viajes por el espacio público. Sin embargo, este dispositivo protésico que es el walkman (el discman, después, el iPod, hoy) no hace que el individuo anule los espacios públicos por los que pasea, como piensa Yúdice, sino más bien los dota de un nuevo sentido, es decir, los "resignifica". Es lo que sugiere Iain Chambers (1995) al escribir cómo el oyente ambulante transforma

6. Conviene señalar, sin embargo, que el volumen alto de los nuevos sistemas de reproducción sobrepasa el límite de su intimidad, y lo privado se vuelve público. Los teléfonos móviles, por ejemplo, si bien no fueron creados inicialmente para ello, permiten los dos tipos de modalidad de escucha, privada y compartida, y ponen en duda, por tanto, los límites entre lo público y lo privado. 
el aparente solipsismo de los auriculares "musicalizando" de manera individual el espacio público. Al movernos por la ciudad con nuestro walkman, construimos una identidad auditiva nómada a medida que el sujeto recrea activamente los paisajes que le rodean, que cambian y se modifican cuando los vemos musicalizados con la banda sonora que hemos elegido. Para Chambers, esta recreación del espacio público por medio del walkman forma parte de un proceso más amplio en el que la elección de la música, así como las asociaciones que hacemos con otros signos o lugares están en relación con el entorno en el cual nos hemos formado, de tal forma que al "mirar" la ciudad a través de los sonidos del walkman, la estamos mirando desde un punto de vista en el que hay en juego tantas elecciones personales como determinaciones sociales que nos permiten darle significado a lo que vemos. Como recuerda Cristina Peñamarín:

La elaboración imaginativa de cada sujeto no está aislada de los procesos sociales de formación de lugares comunes propios de comunidades interpretativas y de corrientes. Todo espacio cultural e imaginario localizado, toda localidad o territorio, está atravesado por corrientes de diversa relevancia situacional y global (Peñamarín, 2008: 72)

El walkman se convierte entonces en un medio con el cual negociamos nuestro entorno y le dotamos de nuevos significados a cada escucha, proporcionando una experiencia musical (y visual) distinta para cada viaje.

\section{La muerte del audiófilo}

Si bien la principal consecuencia del nacimiento de los auriculares es la salida del individuo al espacio público, enchufado a un walkman que le permite transportar su música de un lugar a otro, los hay quienes prefieren quedarse en su casa y disfrutar íntimamente de la belleza de la música y el sonido grabado conectando unos buenos auriculares al equipo domestico: surge así la figura del audiófilo, el oyente solitario por excelencia. En realidad, la era del audiófilo se inaugura con los equipos de alta fidelidad, los cuales van prestando poco a poco una calidad de sonido inmejorable, pero el uso de auriculares hace que esta experiencia se generalice y la escucha se convierta en un placer por derecho propio que busca explorar el registro dinámico (la disparidad entre las partes de sonido más fuerte y las más suaves) de las piezas y la belleza de los detalles y matices sonoros. El neurocientífico y músico estadounidense Daniel Levitin describe su primer contacto con los auriculares de la siguiente manera: 
Los nuevos artistas a los que yo estaba escuchando exploraban por primera vez la mezcla estéreo. Como los altavoces que venían con mi equipo estéreo [...] no eran muy buenos, yo no había oído nunca con tanta profundidad como con los auriculares: el emplazamiento de los instrumentos tanto en el campo izquierda-derecha como en el espacio (reverberante) delante-atrás. Para mí, los discos dejaron de ser sólo las canciones, y pasaron a ser el sonido. Los auriculares me abrieron un mundo de colores sónicos, una paleta de matices y detalles que iban mucho más allá de los acordes y la melodía, la letra o la voz de un cantante concreto (Levitin, 2008: 9-10).

La búsqueda de la reproducción más fiel del sonido y de la escucha profunda y envolvente se convierte para muchos en una nueva forma de placer musical, lo que conduce al nacimiento de toda una generación de aficionados a los equipos de alta fidelidad y al sonido de alta calidad. Esta generación de oyentes prefiere el sonido analógico al digital, ya que éste último, si bien tiene una transparencia inmejorable comparado con los viejos reproductores de audio (vinilo, cassette, etc.) hace que la reproducción sonora sea notablemente fría y carente de cuerpo. Argumentan que el sonido analógico es más cálido, orgánico y envolvente que el sonido digital, que, por el contrario, suena demasiado limpio, plano y superficial. Esto es porque en el sonido analógico toda la gama dinámica permanece en su sitio y es posible descubrir miles de detalles sonoros y musicales distintos en cada canción. El sonido digital tiene que reducir el rango dinámico de las piezas para comprimir la información en el archivo, por esos su sonido es más lineal y menos profundo. Así pues, un rango dinámico amplio como el que permite el sonido analógico crea en el escucha una mayor sensación de espacialidad y hace más sencillo diferenciar instrumentos individuales.

El problema con la generación audiófila es que los equipos de sonido y auriculares que permiten disfrutar de este tipo de experiencia en todo su esplendor son demasiado caros y no están al alcance de cualquiera. Sólo unos pocos pueden permitir costarse un sistema de sonido completo que lleve, esta vez literalmente, la sala de conciertos al propio hogar. Quizá sea éste uno de los factores por los que la "retórica de las grabaciones" se ha desplazado actualmente a otra parte. Según Mark Katz, el sonido grabado como reproducción fiel de la realidad, que era el principal reclamo publicitario (y retórico) de la industria, ha sido prácticamente eliminado con la llegada de los MP3 y el iPod, cuyos anuncios rara vez hacen hincapié en la belleza y calidad del sonido. En su lugar, el estilo típico de 
estos anuncios presenta a los iPods como accesorios para la ropa, “conectados" o "enchufados" a los pantalones vaqueros, camisas y cinturones (véase Tommasini, 2007). Se han convertido en música portátil, vestible (weareable music), una variedad más de esa computación vestible que se prepara para ser el nuevo paradigma tecnológico. Michael Bull (2008), que ha analizado detenidamente el fenómeno iPod llegando a considerarlo como "el primer icono cultural del siglo XXI", destaca por encima de todo valores como la movilidad, la estética y la funcionalidad como claves del éxito de este reproductor portátil, así como la posibilidad de que los usuarios lleven su mundo auditivo "en la palma de su mano", como puede verse claramente en la imagen siguiente, verdadero resumen visual de lo que venimos explicando:

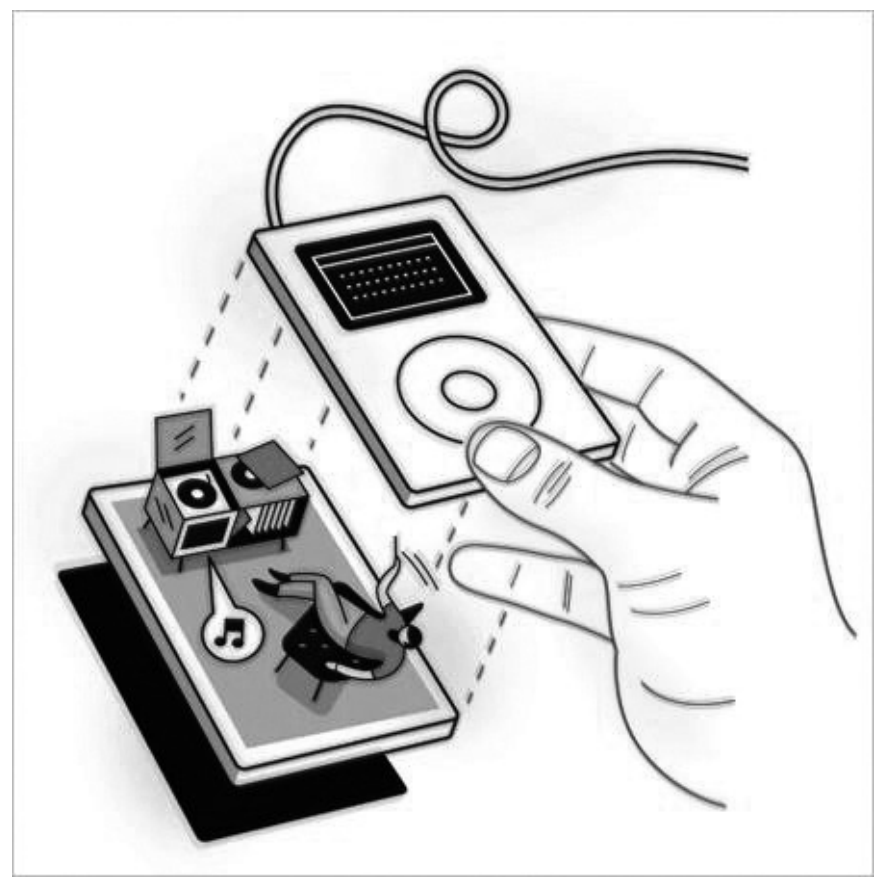

FIGURA 1: Harry Campbell (The New York Times, November 25, 2007)

Así pues, poco importa la calidad del sonido mientras que la música sea fácilmente portable y accesible y el reproductor haga juego con 
nuestra ropa y estilo personales. ${ }^{7}$ De ahí la gran variedad de diseños de reproductores portátiles disponibles a tal fin.

La calidad del sonido no es un problema para los jóvenes de la llamada "generación iPod", ya que, al haber nacido inmersos en la era de la información (los denominados "nativos digitales"), han crecido acostumbrados a una música dinámicamente comprimida y al sonido metálico y plano del MP3 y otros formatos musicales digitales. De hecho, prefieren este tipo de sonido al de otros formatos como el vinilo o el $\mathrm{CD}$, del mismo modo que las generaciones anteriores prefieren el sonido granulado del vinilo y creen que la música digital no suena igual que un $\mathrm{CD}$ o el sonido analógico de un buen tocadiscos. La generación iPod ha crecido con el estándar de $128 \mathrm{kbps}$ de iTunes (la tienda online de Apple que sirve como plataforma de descarga de música para el iPod), lo que supone una música totalmente comprimida y muy lejana de la calidad de un $\mathrm{CD}$ o de un disco de vinilo. Para estos jóvenes es más importante el acceso a un amplio catálogo, como el ofrecido por iTunes, que la calidad de la música que descargan y escuchan en los auriculares de su iPod; es decir, es más importante la cantidad que la calidad. Por eso, los hay quienes ya han anunciado la muerte de la era del audiófilo como consecuencia del acceso generalizado a una música dinámicamente comprimida y de baja calidad sonora.

\section{El darwinismo de lo sonoro}

La música que escuchamos hoy día suena cada vez más alta, más fuerte, fenómeno que ha sido objeto de debate entre discográficas, productores, ingenieros, intérpretes y fans y que se conoce como "la guerra del volumen" o the loudness war (Levine, 2007). En general, la vida es mucho más ruidosa de lo que lo era hace años y la música tiene que competir con el resto de sonidos que habitan nuestro entorno. La tendencia a aumentar el volumen del sonido empieza con la difusión de los juke boxes, que al ser alquilados en los bares y en otros lugares públicos, y por tanto destinados a ser usados a alto volumen, provocaron "el surgimiento de una música que debería escucharse a todo volumen" (Eco, 2001: 293). Esta práctica se extendió después a los discos y la radio como una estrategia

7. Como recuerda García Canclini (2007), el cuerpo siempre ha sido portador de cultura, en forma de posiciones y actitudes, vestimentas, formas de pintárselo, etc. Sin embargo, la retórica de los reproductores de música portátiles como el iPod reduce el cuerpo a lo que sirve para portar música acorde con una ropa y una estética que exhibe estilos de vida y actitudes que distinguen, y que es producto de una mercadotecnia que se dirige a los jóvenes de una determinada generación, en este caso, la bautizada como "generación iPod". 
por parte de la industria de buscar la atención del oyente por medio de un volumen alto y fuerte. Para la industria musical, un volumen alto se traduce en una mayor atención y, como consecuencia, en mayores posibilidades de hacer negocio, según la lógica simplista del "más es mejor" propia de la "modernidad sólida" o "pesada" descrita por Bauman, esto es, "la modernidad obsesionada por el gran tamaño, la modernidad de 'lo grande es mejor', o del tipo, 'el tamaño es poder, el volumen es éxito'” (Bauman, 2007: 122; la cursiva es mía).

La tendencia a aumentar el volumen también se observa en los propios consumidores, quienes se ven obligados a subir el volumen de sus reproductores para hacer frente al ruido del mundo exterior si no quieren que éste les imponga sus molestos sonidos. Para un gran número de personas, la música se escucha actualmente "en el camino" (on the road), en los coches, en los auriculares mientras paseamos, mientras hacemos deporte o mientras vamos en metro o en autobús. La música tiene que competir con el sonido del motor del coche, tiene que elevarse por encima del ruido de la calle o del chismorreo de la gente y de los motores en el transporte público. Surge entonces una especie de "darwinismo de lo sonoro" en la que la música de nuestros reproductores lucha por sobrevivir con el resto de sonidos del entorno, y lo hace aumentando el volumen, tanto en el terreno de la producción (el volumen de los discos es cada vez más alto) como en el de la recepción (tenemos que subir el volumen al máximo para ahogar el resto de sonidos, y utilizar sistemas de asilamiento sonoro con el exterior, como los coches modernos, o los auriculares insonorizados).

Este darwinismo de lo sonoro se traduce en un bombardeo musical constante y a un volumen cada vez más alto, lo deseemos o no. Como señala Oliver Sacks, muchos de nosotros estamos continuamente conectados a reproductores de MP3 como el iPod, "inmersos en conciertos de nuestra propia elección que duran todo el día [...] y para aquellos que no están conectados surge una música interminable, inevitable, y a menudo de una intensidad ensordecedora, en restaurante, tiendas y gimnasios". Este bombardeo musical, continua Sacks, "causa cierta tensión en nuestros sistemas auditivos, exquisitamente sensibles, que no pueden sobrecargarse sin que haya consecuencias funestas. Una de tales consecuencias es que la gente pierde el oído cada vez más" (2009: 71). Esto afecta sobre todo a las generaciones más jóvenes, a la generación iPod y compañía, ya que al ser la música digital que consumen y a la que están acostumbrados de peor calidad debido a la compresión del sonido y al aumento general de los rangos de frecuencia y volumen, sus oídos se ven afectados hasta el 
punto de padecer graves defectos auditivos que pueden acabar en sordera a edades muy tempranas. ${ }^{8}$

Surge entonces la necesidad de una especie de ciencia del medio ambiente sonoro, de una cierta "ecología de los sonidos" que preserve nuestro oído de los ataques de un volumen demasiado alto, como el que actualmente determina nuestra experiencia musical en el espacio público, en ese mundo exterior que también lucha por imponer sus sonidos.

\section{Conclusión: Las redes sociales o el retorno de la interacción}

Como recuerda Yúdice, el que los usuarios del iPod y otros reproductores de música portátiles habiten un universo privado mientras pasean por el espacio público no quiere decir que no pertenezcan a redes de socialización vinculadas a la música. Las tecnologías de la información han hecho posible nuevas formas de interactividad y nuevas maneras de fortalecer los lazos de afiliación y sociabilidad. El éxito de MySpace, YouTube y sitios parecidos hace que hoy en día se esté "produciendo, consumiendo y comentando más música que nunca” (Yúdice, 2007: 50).

La interacción es algo fundamental en estas redes. Las personas no quieren tanto poseer la música físicamente como acceder, compartir y comentarla con otros, según la dinámica relacional propia de las redes sociales de la web 2.0. La colaboración entre usuarios y las recomendaciones toman un papel fundamental que hace de estos sitios auténticos lugares de socialización online. Puede que la música sólo sea una excusa o pretexto para esta socialización, pero lo cierto es que se generan amplias redes de contactos que animan la vida de estos portales. Esto se aprecia sobre todo en las generaciones más jóvenes, en la generación iPod o en los nativos digitales. Como señalan Pisani y Piotet (2009), lo que los jóvenes esperan de Internet es que sea un potente instrumento de socialización, y esto vale tanto para las redes sociales tipo MySpace o YouTube como para sitios directamente relacionados con la música como Last. fm, Pandora o Spotify. Así, para los nativos, estos portales no sirven sólo para escuchar música, sino también para relacionarse con otros, generar amistades, crear comunidades, e incluso encontrar en ellos empleo o relaciones amorosas o sexuales. Para ellos, esto no es algo sorprendente en

8. Como escribe el propio Sacks: "Dichos problemas es de esperar que aumenten exponencialmente para la gente que pone el iPod u otras músicas a niveles demasiado altos. Se dice que más de un $15 \%$ de jóvenes padecen ahora defectos auditivos graves. Escuchar música en un entorno ya ruidoso, utilizándolo para ahogar el otro, casi garantiza la destrucción de células pilosas “ (Sacks, 2009: 163) 
absoluto, sino un hecho más de su vida cotidiana.

Estas prácticas se acercan bastante a lo que en inglés se conoce como hanging out, término que la antropóloga Danah Boyd describe de la siguiente manera: "En una sociedad centrada en la productividad, pensamos que todo debe ser útil y mesurable. 'Hanging out' es otra cosa: significa reunirse y no hacer nada, escuchar música, hablar de lo que se nos ocurra" (Boyd, citado en Pisani y Piotet, 2009: 46). Para los jóvenes, el hanging out es una manera de posicionarse socialmente frente a los demás, de interactuar con ellos, de crear relaciones sociales y, por tanto, una identidad: es una forma de dar una imagen de uno mismo y de que esa imagen sea recibida por otros, y "el hecho de que no haya una acción concreta y mesurable no le quita valor" (Boyd, ibid). El valor está en la misma relación, en el hecho de que los jóvenes se interesan por sus amigos y les gusta pasar tiempo con ellos allí donde se encuentren, que hoy día pasa considerablemente por el espacio público digital de la web y los sitios de redes sociales, lugares fantásticos para el hanging out.

Asimismo, la relación que mantienen estos jóvenes con la información es también muy distinta a la de las generaciones anteriores. El exceso y la sobrecarga de información no les preocupa y a diferencia de sus padres, que solían querer mantener en secreto cualquier información que tuvieran ("el conocimiento es poder", era su divisa), a ellos les gusta compartir y difundir la información en cuanto la reciben ("compartir el conocimiento es poder”, es su divisa) según la lógica de las redes peerto-peer o P2P (Pisani y Piotet, 2009). La misma relación que tiene con la información la tienen con la música. Por eso, ante un acceso ilimitado que permite una cantidad de música sin igual, como el que permiten estas redes, los nativos digitales la comparten y difunden en cuanto la reciben, en cuanto la escuchan, de lo que se deduce que ésta no ha debido ser muy profunda, sino más bien superficial, de pasada, y en gran medida funcional, ya que actúa como fondo o "acuario" sonoro de sus actividades domésticas y navegaciones por la red.

Sin embargo, lo más importante de estas prácticas no es tanto el carácter de la escucha como el valor de la música como elemento de interacción social online, lo cual supone un retorno parcial a sus orígenes comunitarios. Si bien se trata de una recuperación disociada o desacralizada (pues la música se asocia al mundo del ocio y del no-trabajo, al contrario que en las sociedades primitivas), estas redes sociales permiten reunir a la gente en torno a la música, produciéndola, consumiéndola y comentándola en los mundos virtuales de la red, que si bien no están arraigados a ningún contexto local o territorial concreto, permiten 
nuevas formas de "anclaje" espaciotemporal, inmediato y telepresencial. La sensibilidad que caracteriza a este nuevo oyente musical no es tanto estética como tecnológico-ociosa, siendo la experiencia comunitaria y relacional más importante que el goce estético. Por lo tanto, una gran parte del consumo, placer y significado de la música en nuestras sociedades industrializadas (y de forma especial en las generaciones más jóvenes), gira actualmente en torno a esta lógica interactiva, relacional y conectiva que define la web 2.0 y configura los nuevos modos de ser y estar en el mundo contemporáneo. La música resignifica así sus orígenes grupales y comunitarios bajo nuevos medios, prácticas y lenguajes: los propios de la sociedad digital y la cibercultura.

\section{Bibliografía}

Abril, G. (2005). Teoría general de la información. Datos, relatos y ritos. Madrid: Cátedra. Adorno, Th. W. (2009). Disonancias. Introducción a la sociología de la música. Obra completa, 14. Madrid: Akal.

Attali, J. (1995). Ruidos. Ensayo sobre la economía política de la música. Madrid: Siglo XXI.

Baudrillard, J. (1989). Cool Memories. Barcelona: Anagrama.

Bauman, Z. (2007). Modernidad líquida. Buenos Aires: Fondo de cultura económica.

Benjamin, W (1986): “El narrador: consideraciones sobre la obra de Nicolai

Leskov". Sobre el programa de la filosofía futura y otros ensayos. Barcelona: PlanetaAgostini.

Blacking, J. (2006). ¿Hay música en el hombre? Madrid: Alianza.

Bull, M. (2008). Sound moves: iPod culture and urban experience. New York: Routledge.

Chambers, I. (1995). Migración, cultura, identidad. Buenos Aires: Amorrortu.

Eco, U. (2001). Apocalípticos e integrados. Barcelona: Lumen y Tusquets.

García Canclini, N. (2007). Lectores, espectadores e internautas. Barcelona: Gedisa.

Giddens, A. (1993): Consecuencias de la modernidad. Madrid: Alianza.

Levine, R. (2007). “The Death of High Fidelity. In the age of MP3s, sound

quality is worse than ever". En Rolling Stone, News, 27 December.

Levitin, D. J. (2008). Tu cerebro y la música. El estudio científico de una obsesión humana. Barcelona: RBA Libros.

Peñamarín, C. (2008). ¿Hay vida en el espacio público mediatizado? CIC. Cuadernos de información y comunicación, $\mathrm{n}^{\circ}$ 13, 2008.

Peterson, R. A., y Ryan, J. (2005). "La musa sin cuerpo”. En Howard, Philip N. y Jones, Steve (Eds.): Sociedad on-line: Internet en contexto. Barcelona: Editorial UOC.

Pisani, F. y Piotet, D. (2009). La alquimia de las multitudes. Cómo la web está cambiando el mundo. Barcelona: Paidós. 
Rifkin, J. (2000): La era del acceso: la revolución de la nueva economía.

Barcelona: Paidós.

Sacks, O. (2009). Musicofilia. Relatos de la música y el cerebro. Barcelona: Anagrama.

Segalen, M. (2005). Ritos y rituales contemporáneos. Madrid: Alianza.

Sennett, R. (2002). El declive del hombre público. Barcelona: Península.

Storr, A. (2007). La música y la mente. El fenómeno auditivo y el porqué de las pasiones. Barcelona: Paidós.

Tommasini, A. (2007). Hard to Be an Audiophile in an iPod World. En The New York Times, Arts, 25 November.

Yúdice, G. (2007). Nuevas tecnologías, música y experiencia. Barcelona: Gedisa. 